\title{
RADIOLOGICAL ASSESSMENT OF FEMORAL BICONDYLAR ANGLE AMONG PERSONS ATTENDING A TERTIARY HEALTH GARE
}

\author{
Pradhan A, Lama CP, Dhungel S, Ghosh SK
}

Department of Anatomy, Nepal Medical College and Teaching Hospital, Attarkhel, Gokarneshwor-8, Kathmandu, Nepal

\begin{abstract}
Femoral bicondylar angle is the angle between an axis through the shaft of the femur and a line perpendicular to the infracondylar plane. This study aims to assess femoral bicondylar angle measured from radiograph of femur and knee joints obtained from teaching hospitals in Kathmandu Nepal. Total of two hundred AP view radiograph of knee joint were collected, out of which, 50 each were of male right and left knee joint and 50 each were of female right and left knee joint. The mean angle for the right male femur was $7.86^{\circ}$ with the range of $5^{\circ}-10^{\circ}$ and mean angle for the right female femur was $8.82^{\circ}$ with the range of $6^{\circ}-11^{\circ}$. On the left side, bicondylar angle ranged in male from $6^{\circ}-10^{\circ}$ with the average of $7.46^{\circ}$ and in female range was $6^{\circ}-11^{\circ}$ and average was $8.66^{\circ}$. The bicondylar angle was higher in female on both the side, the difference was statistically significant on the left side $(\mathrm{P}=0.004)$ and significant on the right side $(\mathrm{P}=0.001)$. The finding of the study showed the femoral bicondylar angles were greater in right femur than left femur in both sexes. The difference in the bicondylar angle between the right and left femur was statistically insignificant in both sexes. (male $\mathrm{p}=0.144$, female $\mathrm{p}=0.541$ ). The result from this study has shown that femoral bicondylar angles were generally greater amongst the females as compared to the males; greater in right femur than left femur in both sexes.
\end{abstract}

\section{KEYWORDS}

Femoral bicondylar angle, femoral diaphysis, infracondylar plane and measurement of radiograph

\section{CORRESPONDING AUTHOR}

Dr. Allin Pradhan,

Lecturer, Department of Anatomy,

Nepal Medical College Teaching Hospital,

Attarkhel, Gokarneshwor-8, Kathmandu, Nepal,

Email: meallinsh@gmail.com 


\section{INTRODUCTION}

Femoral bicondylar angle or obliquity angle is the angle between an axis through the shaft of the femur and a line perpendicular to the infracondylar plane (intercondylar plane). It usually measures about $8^{\circ}$ to $14^{\circ}$ in adults..$^{1,2}$

When a child is born, the axis of the shaft is perpendicular to the metaphyseal growth front and the angle is zero, ${ }^{1}$ as shown in Fig. 1 . When a 1-year-old child first starts to walk, the medial side of the distal metaphysis grows faster than the lateral side, resulting in the bicondylar angle. ${ }^{1}$ The angle is generally higher in women due to their large pelvis. ${ }^{3,4}$

With evolution, the increase in femoral obliquity angle has been noted in humans ${ }^{1}$ and this angle consistently and significantly greater than $0^{\circ}$ has been a hallmark of hominid bipedality. ${ }^{5}$ This angle helps to bring the knees near the line of gravity of the body which is essential to walk upright in two legs. ${ }^{4,6}$

Gender determination has been accomplished using a variety of femoral dimensions such as the femoral head diameter and angle, ${ }^{7}$ maximum length of femur, epicondylar breadth, bicondylar length and breadth, circumference at the midshaft and bicondylar breadth, ${ }^{8}$ and the femoral neck diameter. ${ }^{9}$ Various studies carried out across the world have determined the feasibility of using the femoral bicondylar angle measured ostelogically and radiologically. This study aims to assess femoral bicondylar angle measured from radiographs of femur and knee joint of both sexes which were obtained from Nepal Medical College and Tribhuvan University Teaching Hospitals in Kathmandu Nepal.

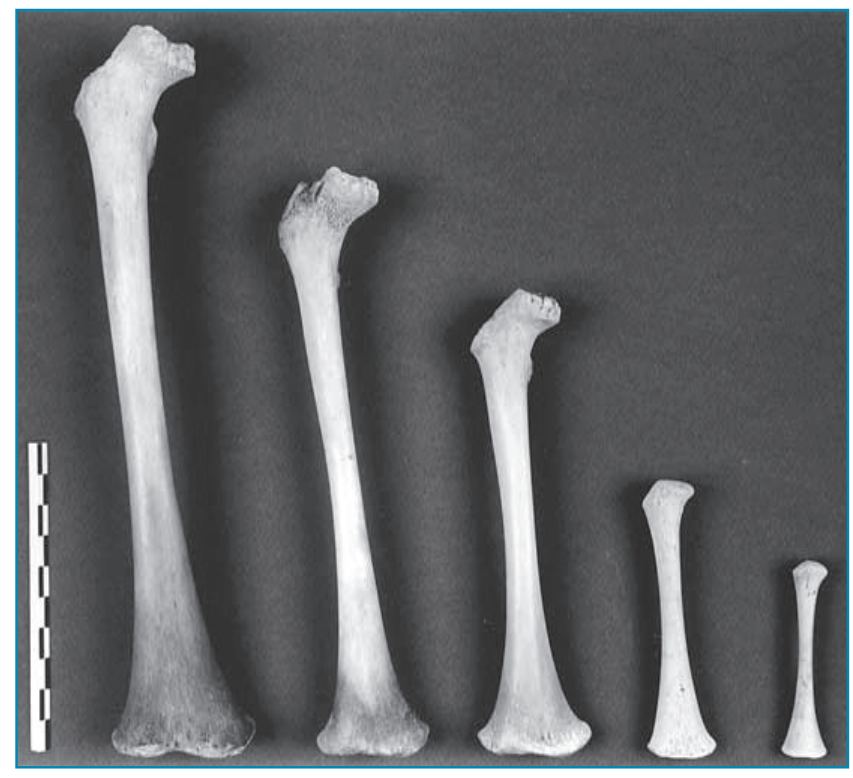

Fig. 1: Femoral diaphysis with the proximal and distal epiphyses removed. The angle shown is with reference to the metaphyseal growthfront. The femora are at ages 7 years, 5 years, 3 years, 7 months, and a month fetus. ${ }^{1}$

\section{MATERIALS AND METHODS}

Total of 200 AP view radiographs of knee joint (which shows distal femur) were collected from NMCTH and TUTH over the period of three months June/August 2018. The radiographs comprised of 50 each of male right and left knee joint (total 100) and 50 each of female right and left knee joint (total 100) irrespective of the same individual. Femoral bicondylar angle were measured from each radiograph using a goniometer, vernier caliper and accessories. The value of mean angle with standard deviation were calculated, T- test were subjected for the statistical analysis using SPSS version 16 and presented in the form of tables and graph.

\section{Procedure of measurement of bicondylar angle}

The inferior margin of both the condyles (infracondylar plane), denoted by XY, represents the horizontal plane. The points A and B marked on the x-ray film that show maximum diameter of shaft at highest point in the $\mathrm{X}$-ray. The points $\mathrm{C}$ and $\mathrm{D}$ marked on the x-ray film, in the supracondylar plane. The axis of shaft was obtained by a line joining the mid points of $A B$ and $C D$, i.e. $F$ and $G$ respectively with $O$ point at infracondylar plane. Therefore, the angle EOF between the axis of shaft and the perpendicular axis (OE) meeting the horizontal line denotes the bicondylar angle. The previous measurement was shown in Fig. 2.

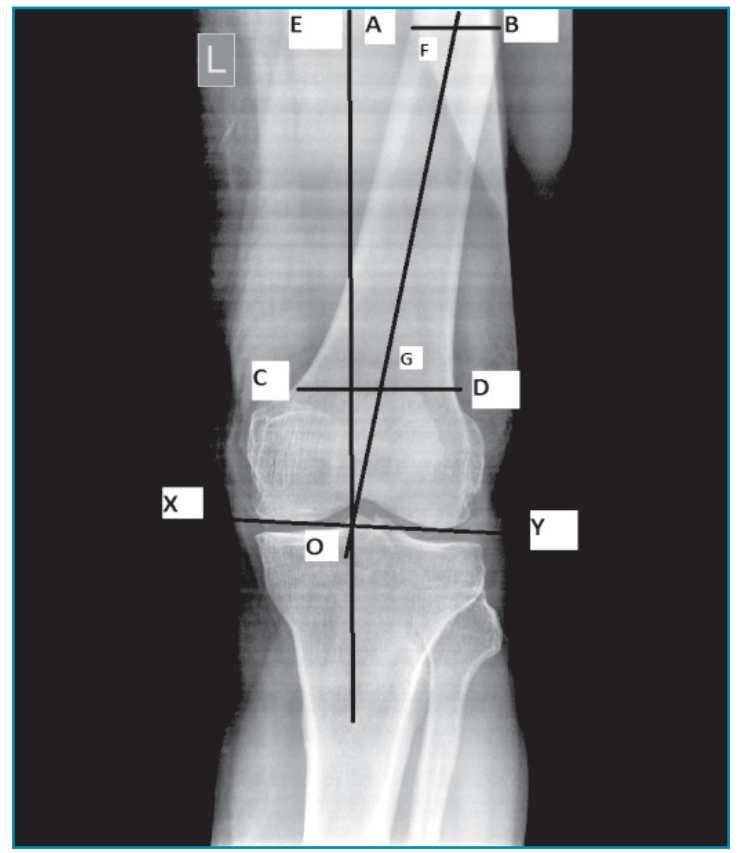

Fig. 2: Showing bicondylar angle

\section{RESULTS}

The values of bicondylar angle obtained in the present study are shown in the Table- 1 . The mean angle for the right male femur was $7.86^{\circ}$ with the range of $5^{\circ}-10^{\circ}$ and mean angle for the right female femur was $8.82^{\circ}$ with the range of $6^{\circ}-11^{\circ}$.On the left side, bicondylar angle ranged in male from $6^{\circ}$ $10^{\circ}$ with the average of $7.46^{\circ}$ and in female range 
was $6^{\circ}-11^{\circ}$ and average was $8.66^{\circ}$. The bicondylar angle was higher in female and on both the side, the difference was statistically significant on the left side $(\mathrm{p}<0.01)$ and the right side $(\mathrm{P}<0.01)$. The finding of the study showed the femoral bicondylar angles were greater in right femur than left femur in both sexes. The difference in the bicondylar angle between the right and left femur was statistically insignificant in both sexes (male $\mathrm{p}=0.144$, female $\mathrm{p}=0.541$ ).

\begin{tabular}{|c|c|c|c|c|}
\hline \multirow{2}{*}{$\begin{array}{l}\text { Bicondylar } \\
\text { angles }\end{array}$} & \multicolumn{2}{|c|}{ Right (n=100) } & \multicolumn{2}{|c|}{ Left $(n=100)$} \\
\hline & $\begin{array}{l}\text { Male } \\
(n=50)\end{array}$ & $\begin{array}{c}\text { Female } \\
(n=50)\end{array}$ & $\begin{array}{l}\text { Male } \\
(n=50)\end{array}$ & $\begin{array}{c}\text { Female } \\
(n=50)\end{array}$ \\
\hline Range & $5-10^{\circ}$ & $6-11^{\circ}$ & $6-10^{\circ}$ & $6-11^{\circ}$ \\
\hline Mean & $7.86^{\circ}$ & $8.82^{\circ}$ & $7.46^{\circ}$ & $8.66^{\circ}$ \\
\hline S.D. & 1.38 & 1.33 & 1.30 & 1.28 \\
\hline P value & \multicolumn{2}{|c|}{$\mathrm{P}=0.001$} & \multicolumn{2}{|c|}{$\mathrm{P}=0.004$} \\
\hline
\end{tabular}

\section{DISCUSSION}

The angulations of the femoral shaft as well as the anatomical features of the pelvis are morphological patterns related to mechanical requirements for erect posture and bipedal gait. Bicondylar angle of the femur is thus believed to play a significant role in the postural as well as the bipedal gait of an individual. ${ }^{15}$ The bicondylar angle starts at $0^{\circ}$ at birth and then increases progressively with growth to reach adult values of at least 6- $8^{\circ}$ between 4 and 8 years postnatally. In adults, the mean values are between $8-11^{\circ}$ and the maximum range is between $6-14^{\circ} .^{1}$

McMinn, ${ }^{9}$ reported in the textbooks of anatomy, that the bicondylar angle is mentioned to have higher values in female linked with their broader pelvis and short stature. Tardieu and Damsin ${ }^{1}$ and Biwas ${ }^{20}$ had reported statistically insignificant sexual dimorphism of angle on both the side; while Igbigbi and Sharrif ${ }^{13}$ reported significant sexual dimorphism bilaterally in the adult Malawian population. Similarly in our study bilateral sexual dimorphism was found to be statistically significant. ( $p<0.01$ on right side and left side). Singh and Singh, ${ }^{12}$ had showed significant gender difference only in left side.

Singh and Singh ${ }^{12}$ and Mahajan ${ }^{14}$ have shown bicondylar angle was more on right side of the both the gender which is similar to our study. In our study, the bicondylar angle of the right femur was more than the left in both the genders; but the side difference was not significant in both sexes $(p>0.5$ among male and female).

In contrast, Pearson and Bell, ${ }^{10}$ Pandya, ${ }^{4}$ Ukhoha, ${ }^{15}$ Chandrasekaran, ${ }^{16}$ Sharma $^{18}$ and Sintakala ${ }^{19}$ have shown that the bicondylar angle was greater on left side of the femur of both sexes.

Pearson and Bell, ${ }^{10}$ Ukhoha, ${ }^{15}$ Chandrasekaran, ${ }^{16}$ Sharma ${ }^{18}$ and Sintakala ${ }^{19}$ and Biswas ${ }^{20}$ have reported the left femoral bicondylar angle of male to be greater than right male femur. However, on the contrary, Singh and Singh, ${ }^{12}$ Pandya $^{4}$ and Mahajan ${ }^{14}$ have shown bicondylar angle of right side to be greater than left bicondylar angle in male femur which was similar to our study.

Similarly, different studies ${ }^{4,10,15,16,18-20}$ have shown left bicondylar angle to be greater than right in female femur, whereas Singh and Singh ${ }^{12}$ and Mahajan ${ }^{14}$ have shown right bicondylar angle to be greater than left side of the female femur; similar were the findings in our study.

Mechanical factors such as differential strain and stress experienced by the femur due to diverse physical activity coupled with the variation in the biological factors such as genetic constitution, hormonal environment, growth factor, nutrition etc could be responsible for variation of obliquity of shaft obtained in different studies. ${ }^{4}$

Limitation of the study: The radiographs of the right and left sides were not of the same individual, since exposure of both sides was not possible. Therefore, in the present study comparative study could not be employed between femoral bicondylar angle of right and left of same individual.

In conclusion, the result from this study has shown that femoral bicondylar angles were generally greater amongst the females as compared to the males and also shows that the femoral bicondylar angles were greater in right femur than left femur in both sexes.

\section{ACKNOWLEDGEMENT}

We would like to thank the Radiology Departments of Nepal Medical College Teaching Hospital, Attarkhel and Tribhuvan University Teaching Hospital, Maharajgunj, Kathmandu, Nepal for their support.

\section{REFERENCES}

1. Tardieu C, Damsin JP. Evolution of the angle of obliquity of the femoral diaphysis during growth correlations. Surg Radiol Anat 1997; 19: 91-7.

2. Tardieu C, Trinkaus E. Early ontogeny of the human femur. Amer J Phys Anthropol 1995; 95: 183-95.

3. LoveJoy CO, Heiple KG. A reconstruction of the femur of Australopithecus Africanus. Amer J Phys Anthropol 1970; 32: 33-40.

4. Pandya AM, Singel TC, Patel MM. A study of the femoral bicondylar angle in the Gujarat region. $J$ Anat Soc India 2008; 57: 131-4.

5. Trotter M, Glesser GC. A re-evaluation of estimation 
of stature on measurements of stature taken during life and of long bones after death. Amer J Phys Anthropol 1958; 16: 79-123.

6. Albanese J, Eklics G, Tuck A. A metric method for sex determination using the proximal femur and the fragmentary hipbone. J Forensic Sci 2008; 53: 1283-8.

7. Spradley KM, Jantz RL. Sex estimation in forensic anthropology: Skull versus post cranial elements. $J$ Forensic Sci 2011; 56: 289-96.

8. Alunni-Perret V, Staccini P, Quatrehomme G. Re-examination of a measurement for sexual determination using the suproinferior femoral neck diameter in a modern European population. J Forensic Sci 2003; 48: 517-20.

9. McMinn RMH. Last's Anatomy regional and applied, in osteology of the lower limb. $9^{\text {th }}$ ed. Churchill Livingstone London 1994; 221-4.

10. Pearson K, Bell J. A study of long bones of the English skeleton, Part-I femur, in the influence of race, side and sex. Cambridge University press, London 1919; 128-30.

11. Heiple KG, Lovejoy CO. The distal femoral anatomy of Australopithecus. Amer J Phys Anthropol 1971; 35: 75-84.

12. Singh SP, Singh SS. Study of the obliquity of the shaft of the femur (bicondylar angle) in Indians. $J$ Anat soc India 1974; 23: 57-60.
13. Igbigbi PS, Sharrif M. The bicondylar angle of adult Malawians. Amer J Orthop 2005; 34: 291-4.

14. Mahajan A, Seema, Khurana BS, Gandhi D. Study of the obliquity of the shaft of the femur in the Punjab region. Int J Bas App Med Sci 2011; 1: 40-3.

15. Ukoha U, Oranusi C, Uzozie O, Okafor J, Ogugua P, Metu A. Radiological assessment of the femoral bicondylar angle in a Nigerian population. Tropical J Med Res 2011; 15: 45-7.

16. Chandrasekaran S, Shastri D. Bicondylar angle of femur in South Indian population - an analytical study. Nat J Bas Med Sci 2011; 1: 124-8.

17. Mistri S, Bhakta A, Mondal GC, Bandyopadhyay M, Kumar S. A Study of obliquity of femoral shaft in Eastern Indian population. Nepal Med Coll J 2012; 14: $9-12$

18. Sharma R, Sharma S, Jehan M .Sexual dimorphism of the femoral bicondylar angle in Gwalior, Madhya Pradesh region. Int $J$ Healthcare and Bio Med Res 2014; 2: 38-45.

19. Sintakala C, Manandhar P, Sah A. Osteological and radiological study of femoral bicondylar angle among Nepalese population. Int Arch Bio Med Clin Res 2017; 3: 121-6.

20. Biswas A, Bhattacharya S, A morphometric and radiological study of the distal end of femur in West bengal population. Ital J Anat Embryol 2017; 122: 39-48. 